\title{
A COMPARATIVE STUDY OF METHODS FOR TREATING FRACTURES OF THE DISTAL HALF OF THE FEMUR
}

\author{
TUDOR L. THOMAS, BERNARD F. MEGGITT
}

\author{
From the Department of Orthopaedic Surgery, Addenbrooke's Hospital, Cambridge
}

\begin{abstract}
A comparative study of methods for treating fractures of the distal half of the femur was carried out prospectively in the five-year period January 1973 to December 1977. The three methods compared were conservative treatment on a Thomas' splint, application of a knee-hinged cast-brace at five to seven weeks, and intramedullary nailing.

The time in bed, in hospital and to union were compared as was the rate of functional recovery of the knee.

It is concluded that the cast-brace provides a safe reliable method of treatment, combining the advantages of non-operative management with the early mobilisation possible with intramedullary fixation but without the disadvantages of surgical treatment.
\end{abstract}

Mid-shaft and distal fractures of the femur may be treated with traction, with traction followed by a standard cast-brace which is hinged at the knee, or with an intramedullary nail. Between 1973 and 1977, a study was made to compare these three methods of treatment.

\section{MATERIAL AND METHOD}

Clinical trials were carried out from January 1973 to December 1977 at Addenbrooke's Hospital, Cambridge. During this time 241 patients presented with fractures of the femoral shaft, 81 of whom had acute traumatic fractures of the distal half with no other significant injuries; these 81 patients were the subjects in the study. Patients with other injuries which would interfere with functional recovery were excluded. For all patients, the progress of the fracture and functional recovery were assessed clinically and radiologically.

Initial treatment for all fractures was reduction with proximal tibial skeletal traction, on a balanced Thomas' splint. Thereafter allocation to each treatment group was by random selection. It became apparent, however, that in some cases early mobilisation was especially required: for these patients and in those where an unsatisfactory initial reduction persisted it was felt that intramedullary nailing was particularly indicated. Inevitably this meant that completely random selection was not possible but as the number of each type of fracture, for example comminuted, transverse, spiral or oblique, treated by each method was approximately equal, this seems unlikely to have influenced the results.

Compound wounds were debrided and local antibiotics instilled. Systemic antibiotics were also given. Thereafter the patients were divided into three treatment groups.

Group 1. Traction was maintained throughout with early muscular activity followed, when the fracture was "sticky", by active mobilisation of the knee using a flexion piece or Fisk splint. Once the fracture was considered sufficiently stable on clinical and radiological assessment the traction was removed, the patient mobilised on crutches and discharged. Progression from partial to full weight- bearing was allowed when the fracture had united. Thirty patients were treated in this way, their ages ranging from 16 to 70 years with an average of 35 years.

Group 2. A cast-brace of the standard long-leg type with a hinged knee was applied once the fracture was at the "sticky" stable phase with early callus formation. The method of application was that described by Mooney et al (1970).

Connolly and King (1973) have shown by cineradiography that most mid-shaft and distal femoral fractures have stabilised by six weeks. In a few of the initial cases in our series an attempt was made to apply the cast-brace at three to four weeks. Problems were encountered which will be described later and our subsequent management was to apply the brace at five to seven weeks. The patient was then mobilised with crutches and discharged with maximal "comfortable" weight-bearing allowed and active flexion of the knee encouraged. When the patient was able to bear full weight the cast-brace was removed and union assessed clinically and radiologically. Twenty-six patients were treated by this method, their ages ranging from 17 to 72 years with an average of 29 years.

Group 3. Open reduction and fixation with an intramedullary nail was employed in this group. This was not carried out as an immediate emergency procedure but usually took place at about a week to 10 days. Early physiotherapy was given with the patient on crutches but not bearing weight, and after removal of the sutures the patient was discharged from hospital. Weight-bearing was gradually increased, full weight-bearing being allowed when the fracture was considered to be radiologically united. Twenty-five patients underwent fixation with intramedullary nails of which 18 were Küntscher nails and seven ASIF nails. Their ages ranged from 18 to 77 years with a mean of 27 years. Removal of the nail was planned for 12 months later.

Outpatient physiotherapy for all patients was continued until walking was safe and the muscles and joints of the limb had recovered.

In all groups the sex ratio was approximately two men to each woman. The fractures were largely due to the same causes, 70 to 80 per cent occurring in motor cycle or car accidents. Compound fractures occurred in nine patients of the traction group and in seven in each of the other two groups.

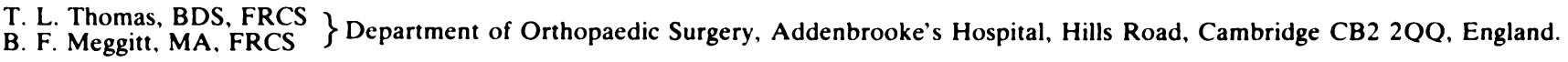
Requests for reprints should be sent to Mr T. L. Thomas.

(1) 1981 British Editorial Society of Bone and Joint Surgery 0301-620X/81/00210003\$2.00 


\section{RESULTS}

Problems with bone healing and infection

Traction group. In two patients delayed union occurred with mobility of the fracture and no callus visible on the radiograph, at 14 weeks in one patient and at 20 weeks in the other; both fractures subsequently united after intramedullary nailing and bone grafting. Malunion occurred in four of this group with 15 to 20 degrees of varus in two patients and 20 degrees of posterior angulation in another two. Shortening of two centimetres occurred in two patients and shortening of three centimetres in a further two. These problems were all due to inadequate maintenance of reduction during traction. Pin-track infection developed in two patients, at eight and 10 weeks respectively; the tracks healed fairly rapidly after removal of the pin and substitution with skin traction. Therefore, 12 patients out of 30 developed significant complications.

Traction followed by a cast-brace. There were no cases of delayed union. Two patients had a varus deformity of 10 and 15 degrees respectively, but this deformity was present when on traction and was not correctable when the brace was applied. Two patients developed 20 degrees of posterior angulation during the application of the cast-brace and this necessitated removal of the brace and reapplication with more posterior support. These two cases occurred at the beginning of the series when an attempt was made to apply the cast-brace at three weeks. Not only did this produce the malposition during application but there also seemed a tendency for some shortening and angulation to occur when the cast loosened as the swelling was absorbed. In all subsequent cases the cast-brace was applied between five and seven weeks when the fracture was in what we call the "sticky stable callus stage", able to move but unlikely to deform. Four cases out of the 26 treated therefore showed a significant complication but two of these problems would not occur now with our present technique.

Intramedullary nailing. There was one case of delayed union in a woman of 77 years where union was thought to have occurred at 26 weeks. One patient with a nailed comminuted femoral fracture developed a late deformity, with external rotation measuring 20 degrees. There was one case of deep infection in a 20-year-old man and this occurred shortly after the nail was inserted. Subsequent sequestration occurred in the lower femoral shaft which required three sequestrectomies and finally a bone graft. The bone did unite at 20 weeks but the treatment was continued for three years. There were therefore three significant complications in this group of 25 patients; there was, in addition, one patient in whom knee flexion stuck at 30 degrees, requiring subsequent quadricepsplasty.

There were no cases of non-union or refracture in any of the groups. The results are summarised in Table I. Time factors

We looked at time spent in bed, the time in hospital, and
Table I. Summary of healing problems

\begin{tabular}{|l|c|c|c|}
\hline \multicolumn{1}{|c|}{ Problem } & $\begin{array}{c}\text { Traction } \\
\text { (30 patients) }\end{array}$ & $\begin{array}{c}\text { Cast-brace } \\
\text { (26 patients) }\end{array}$ & $\begin{array}{c}\text { Nailing } \\
\text { (25 patients) }\end{array}$ \\
\hline Delayed union & 2 & - & 1 \\
Malunion & 4 & $2+2^{*}$ & 1 \\
Shortening & 4 & - & - \\
$\begin{array}{l}\text { Pin-track or nail } \\
\text { infection }\end{array}$ & 2 & - & 1 \\
Fixed flexion & - & - & 1 \\
\hline Total & 12 & 4 & 4 \\
\hline
\end{tabular}

*Threatened malunion

Table II. Time factors in femoral shaft fractures

\begin{tabular}{|l|r|r|r|}
\hline \multicolumn{1}{|c|}{ Period } & $\begin{array}{c}\text { Traction } \\
(30 \text { patients })\end{array}$ & $\begin{array}{c}\text { Cast-brace } \\
(26 \text { patients })\end{array}$ & $\begin{array}{c}\text { Nailing } \\
(25 \text { patients })\end{array}$ \\
\hline In bed (weeks) & $13.2(12-20)$ & $6.3(5-9)$ & $3.5(2-7)$ \\
In hospital (weeks) & $15.3(13-22)$ & $7.0(6-9)$ & $5.4(3-9)$ \\
To union (weeks) & $16.5(14-26)$ & $15.1(12-18)$ & $13.0(10-22)$ \\
\hline
\end{tabular}

the time to union and the figures are summarised in Table II. In the nailing group, the removal of the nail is undertaken after about one year, the second operation involving on average two to three days in bed, three to five days in hospital and two weeks of incapacity; these periods must also be considered in relation to this comparison.

\section{Rehabilitation}

The most consistently reported disability with nonoperative treatment of a fractured femur is malfunction of the knee caused by stiffness and weakness, a disability observed in 30 to 50 per cent of patients in some series.

In the Second World War it was stated that a soldier who had had a fracture of the femur was unlikely to return to duty, not because of malunion or non-union of the fracture but because of disability resulting from stiffness of the knee (Young 1942). Table III is a summary of the pattern of recovery of the knee. At 16 weeks a range of over 90 degrees was obtained by comparable numbers of patients in the traction and cast-brace group, but by slightly more of those with internal fixation. At 24 weeks the cast-braced patients showed the highest percentage of good results. One patient with a nail, with knee flexion fixed at 30 degrees, required a quadricepsplasty at 24 weeks but achieved almost full flexion eight weeks later. The final recording of all patients between 24 and 52 weeks showed that full flexion had recovered in 83,89 and 88 per cent respectively in the three groups.

Attempts at assessing the differences in the use of walking supports and physiotherapy and in muscle recovery were unproductive. The motivation of early 
Table III. Knee recovery in femoral shaft fractures

\begin{tabular}{|c|l|l|l|l|}
\hline $\begin{array}{c}\text { Time } \\
\text { (weeks) }\end{array}$ & $\begin{array}{c}\text { Flexion } \\
\text { (degrees) }\end{array}$ & $\begin{array}{c}\text { Traction } \\
(30 \text { patients })\end{array}$ & $\begin{array}{c}\text { Cast-brace } \\
(26 \text { patients })\end{array}$ & $\begin{array}{c}\text { Nailing } \\
(25 \text { patients })\end{array}$ \\
\hline 16 & $<60$ & 1 & 1 & 1 \\
& $60-90$ & 15 & 12 & 8 \\
& $>90$ & $14(47$ per cent $)$ & $13(50$ per cent $)$ & $16(64$ per cent $)$ \\
\hline 24 & $<60$ & 0 & 0 & 1 \\
& $60-90$ & 5 & 2 & 4 \\
& $>90$ & $25(83$ per cent $)$ & $24(92$ per cent $)$ & $20(80$ per cent $)$ \\
\hline $24-52$ & Full & 83 per cent & 89 per cent & 88 per cent \\
\hline
\end{tabular}

mobilisation and walking in Groups 2 and 3, although not measurable, was regularly observed and subjectively reported at all ages, in contrast to the traction group who were bed-bound for longer.

\section{DISCUSSION}

The object of fracture management is the restoration of optimal function in the shortest time by the safest and most reliable method. Early mobilisation and return to the home environment provide psychological stimuli to recovery. Femoral shaft fractures treated with nailing or a cast-brace are shown in this series to have stable fixation, rapid recovery of knee flexion and early safe mobilisation from bed and hospital. The hospital time averaging five weeks and bony union of 13 weeks in the nailed group are comparable with other reported series (Gillquist, Liljedahl and Rieger 1971). In the castbraced group, the average of seven weeks in hospital and 15 weeks to union is similar to other reports of five to eight weeks and 14 to 15 weeks respectively (Schweigel and Gropper 1974; Patterson and Scott 1975; Weiss 1976). Thus the nailed group averaged two weeks earlier for both discharge and bony union than the cast-braced group, although a further operation and period in hospital must be added for the removal of the nail. The time in bed and in hospital for traction averaged double that for the cast-brace and three times that for nail fixation. Bony union was slower after traction suggesting that early loading of the fracture, braced either internally or externally, exerted a beneficial mechanical stimulus to bone repair.

Early mobilisation and weight-bearing might be considered to carry an increased incidence of malunion and shortening in the cast-braced group. However, this was not seen in this series where application of the cast was delayed until five to seven weeks after the fracture. Attempts early in the series to use the brace before four weeks not only caused malposition during application but also produced shortening and angulation as the cast loosened.

The main disadvantage of open reduction and intramedullary nailing is the risk of deep infection. This has been variously reported in large series with an incidence of up to 10 per cent (O'Brien 1963; Dencker 1965; Carpenter and Couk 1973; Carr and Wingo 1973; Patterson and Scott 1975). In this series one case occurred (four per cent) requiring prolonged treatment to clear the sequestra from the shaft. In many distal femoral fractures, however, internal nailing is inadequate whereas the cast-brace is ideal.

The major disability of the non-operative treatment is loss of knee function through stiffness and weakness with over 30 per cent occurrence reported in large series (Nichols 1963; Stryker, Fussell and West 1970). In the present cast-braced group, rapid recovery of the knee occurred with over 90 degrees of flexion being present in 92 per cent of patients by 24 weeks. Ultimately 89 per cent of this group regained full movement at the knee compared with 88 per cent of the nailed group and 83 per cent of the patients on traction.

The economic implications should be considered. By using the cast-brace, three problems associated with intramedullary nailing are avoided: two operations, the associated potential technical complications and the risk of infection. Yet the patient is freed from hospital only slightly later. A saving of hospital time of eight weeks per patient with a cast-brace as compared to those treated with traction cannot be ignored. In the five-year period of this study, if the $\mathbf{3 0}$ patients treated by traction alone had been treated by cast-bracing the saving would have been approximately 240 bed-weeks-releasing these beds for other patients. A few of our patients managed to return to work in the cast-brace, which represents another modest and probably psychological advantage.

It is concluded that the knee-hinged cast-brace provides a safe reliable method for the treatment of distal femoral fractures, combining the advantages of non-operative management with early mobilisation. Early walking in the cast-brace with a free knee once the fracture is stable appears to provide the optimal therapy for restoration of function.

The concept may be summarised as "not healing the fracture to walk-but walking the fracture to heal". 


\section{REFERENCES}

Carpenter EB, Couk DE. Complications of intramedullary nailing of the femur. J Bone Joint Surg [Am] 1973;52-A:815-6.

Carr CR, Wingo CH. Fractures of the femoral diaphysis: a retrospective study of the results and costs of treatment by intramedullary nailing and by traction and spica cast. J Bone Joint Surg [Am] 1973;55-A:690-700.

Connolly JF, King P. Closed reduction and early cast-brace ambulation in the treatment of femoral fractures. Part I: An in vivo quantative analysis of immobilization in skeletal traction and a cast-brace. J Bone Joint Surg [Am] 1973;55-A:1559-80.

Dencker H. Shaft fractures of the femur: a comparative study of the results of various methods of treatment in 1003 cases. Acta Chir Scand 1965;130:173-84.

Gillquist J, Liljedahl S-O, Rieger A. Fracture of the femur diaphysis: traction or nailing? Acta Chir Scand 1971;137:515-20.

Mooney V, Nickel VL, Harvey JP Jr, Snelson R. Cast-brace treatment for fractures of the distal part of the femur. J Bone Joint Surg [Am] 1970;52-A:1563-78.

Nichols PJR. Rehabilitation after fractures of the shaft of the femur. J Bone Joint Surg [Br] 1963;45-B:96-102.

O'Brien JP. Fractured femoral shafts: a review of 127 consecutive cases, including 53 treated by Küntscher nail fixation. Aust NZ J Surg 1963;33:91-102.

Patterson AH, Scott WN. Ten years' experience with femoral shaft fractures. J Trauma 1975;15:348-55.

Schweigel JF, Gropper PT. A comparison of ambulatory versus non-ambulatory care of femoral shaft fractures. J Trauma 1974;14:474-81.

Stryker WS, Fussell ME, West HD. Comparison of the results of operative and non-operative treatment of diaphyseal fractures of the femur at the Naval Hospital, San Diego, over a five-year period. J Bone Joint Surg [Am] 1970;52-A:815.

Weiss AB. Cast-bracing in femoral shaft fractures. South Med J 1976;69:326-30.

Young RH. The prophylaxis and treatment of the stiff knee following fracture of the femur. Proc $R$ Soc Med 1942;35:716. 